\title{
Ethics and Privacy as Enablers of Learning Analytics
}

\author{
Dragan Gašević, Shane Dawson, and Jelena Jovanović \\ Editors, Journal of Learning Analytics \\ jla.editorial@gmail.com
}

\begin{abstract}
This issue of the Journal of Learning Analytics features a special section on ethics and privacy guest edited by a team of researchers involved in the European Learning Analytics Community Exchange (LACE) project. The issue also features a paper that looks at the use of new methods for the measurement of self-regulated learning. The editorial concludes with a summary of the future changes in the editorial team of the journal.
\end{abstract}

Keywords: learning analytics, data protection, ethics, privacy protection, self-regulated learning

\section{$1 \quad$ INTRODUCTION}

Since the first issue of the Journal of Learning Analytics, we have been exploring the critical factors and drivers that are shaping the formation, growth and maturation of the field of learning analytics. Our previous editorials have looked at a broad spectrum of issues such as critical reflection of the field through methods of scientometrics (Mirriahi, Gasevic, Dawson, \& Long, 2014), widening of the field and multi-disciplinarity (Mirriahi, Dawson, Gasevic, \& Long, 2014), community engagement (Gasevic, Dawson, Mirriahi, \& Long, 2015), links between learning analytics and learning theory (Dawson, Mirriahi, \& Gasevic, 2015), and the importance for challenging the fields' disciplinary assumptions (Dawson, Gasevic, \& Mirriahi, 2015). This editorial continues in that vein touching on privacy and ethics.

Recent indicators suggest that the field is experiencing continued growth and interest from diverse community groups including researchers, practitioners, administrators and government organisations. For example, the forthcoming $6^{\text {th }}$ edition of the International Conference on Learning Analytics and Knowledge (LAK'16) has set some remarkable records including: doubling of the number of submissions compared to LAK'15; and approximately 30\% increase in the number of registered participants. Furthermore, the LAK conference proceedings is the only conference publication among the 20 most cited in the area of educational technology according to the Google Scholar results published mid-2015. We continue to see the growing interest in and impact of learning analytics in many regions outside of North America. For instance, Australia and Europe have significant momentum in analytics adoption among numerous institutions implementing and researching learning analytics and establishing communities of shared interest and practice There is also an increasing amount of activities across Asia and some promising learning analytics research is emerging from Latin America (Edumetricas, 2016). We hope that further development will also commence in Africa, where some outstanding individual contributors to the thought-development in learning analytics are based (e.g., Paul Prinsloo). 
While these positive developments and outcomes provide a solid framework for progression, a number of important challenges remain to be addressed in order to further aid uptake and integration into educational practice. Questions related to privacy and ethics in connection to learning analytics have been an ongoing concern since the early days of learning analytics. Examples of some of the major questions are related to the ownership and protection of personal data, data sharing and access, ethical use of data, and ethical implications of the use of learning analytics in education. It is well recognised that these issues lie at the very heart of the field and that great care must be taken in order to assure trust building with stakeholders that are involved in and affected by the use of learning analytics. This is well exemplified in the now infamous case of the InBloom organization that was forced to shut down its operation after a significant public backlash of users who had voiced a number of ethical and privacy concerns (Horn, 2014; Kharif, 2014). Even though the general concept of InBloom was technologically sound (K.N.C., 2014), the concerns associated with privacy and ethics highlighted the need to better socialise and engage all stakeholders in timely discussions and processes regarding privacy and ethical use of data. Further, systematic research studies need to be conducted with a broad participation and even leadership of different stakeholder groups to unpack complexities of learning analytics adoption and integration among various stakeholder groups. Although we can find some promising contributions (Pardo \& Siemens, 2014; Prinsloo \& Slade, 2015), the topics of privacy and ethics have been widely under-represented in the learning analytics literature.

Frequently we hear of, and participate in, conversations that suggest that ethics and privacy are some of the most critical barriers for the adoption of learning analytics. We would like to take a different perspective to this and encourage the community to see ethics and privacy as enablers rather than barriers. It is natural that learning analytics stakeholders have serious questions related to a number of issues such as protection of their privacy, ownership and sharing of data, and ethics of the use of learning analytics. We would also like to posit that learning analytics can be only widely used once these critical factors are addressed, and thus, these are indeed, enablers rather than barriers for adoption of learning analytics.

\section{IN THIS ISSUE}

This issue features a special section that directly responds to the growing need for research in privacy and ethics in the field of learning analytics. The guest editors of the special section - Rebecca Ferguson, Tore Hoel, Maren Scheffel, and Hendrik Drachsler - have been extensively involved in the organization of a series of workshops in past two years investigating these important topics. The guest editors have compiled an exciting selection of papers based on this work. This special section is indeed a strong step forward towards offering frameworks, (technical) solutions, and guidelines that enable the wide-spread adoption of learning analytics. The editors of the special section also identified a comprehensive list of 21 learning analytics challenges with ethical dimensions that serve as a strong framework for learning analytics implementation, use and research.

This issue also features a paper by Siadaty, Gašević and Hatala who proposed a methodology for micro- 
level measurement of self-regulated learning processes based on the use of trace data. This method expands the existing approaches commonly used for measurement in self-regulated learning that are based on either self-reports or think aloud protocols. The Siadaty et al. method also contributes to the existing body of research knowledge that looks at the connections of learning analytics with selfregulated learning and learning theory as already investigated in some of the previous issues of the Journal of Learning Analytics (Roll \& Winne, 2015; Wise \& Shaffer, 2015).

\section{$3 \quad$ BIG LOSS FOR THE FIELD}

It is with much sadness that we note that our dear friend, colleague, collaborator, and mentor Erik Duval passed away. Erik was an exceptional research leader and a great source of inspiration for many of us. Erik played an important role in the formation of the field of learning analytics. He was a keynote at the first LAK conference in Banff in 2011 and organized the first LAK conference outside of North America (LAK'13 in Leuven in 2013). Although seriously ill, Erik volunteered and served on the SoLAR community until his last moments. Erik graciously participated in the organization of LAK'16 as a sponsorship chair and help enormously in developing the conference and field as a whole. Any success the field now receives lies in large part to Erik's work and efforts. He contributed numerous foundational papers in learning analytics, technology enhanced learning, and human-computer interaction and mentored many young researchers and students. Erik was a tireless advocate for the field and a person who has encouraged many to recognize the importance and potential of learning analytics and to start playing an active role in learning analytics research and development. Our field is endlessly indebted to Erik - his energy, leadership and contributions will be well honored and celebrated for many years. The Society for Learning Analytics Research (SoLAR) has already prepared a series of actions that will honor Erik's legacy and contribution to the field of learning analytics.

Our thoughts are with Erik's family who lost a wonderful husband and a loving father. Erik, thank you; it has been a privilege working with you as a colleague and friend!

\section{EDITORIAL CHANGES}

Since its inception, SoLAR has been built on inclusivity, diversity, equity, and transparency as the key values that lead to the development and sustainment of a heathy research field and community. One of its core principles is to offer opportunities for all members to participate, initiate, and lead different activities, rather than having those roles restricted to a limited group of individuals. With this in mind, we have started a series of changes to our editorial team with the goal to move towards an entirely new editorial team for the research section of the journal by the end of 2016 and the conclusion of volume 3. The change of the editorial team is staged over the course of this entire year to assure the continuity and effective transfer of knowledge and existing practices. As part of this process, Phil Long retired as co-editor in March 2016. We would like to thank Phil for his contributions to the field of learning analytics and the role he has played in the development of the journal. The remaining two editors of the research section of the journal, Shane Dawson and Dragan Gasevic, will retire after the publication of 
issues 2 and 3 of the current volume.

The call for new editors has been announced and we look forward to your applications and to welcoming a new and ambitious editorial team that can bring fresh ideas to move the journal towards its next phase of development and success. It is an exciting time for the field and we feel very honored to be part of it.

\section{REFERENCES}

Dawson, S., Gasevic, D., \& Mirriahi, N. (2015). Challenging Assumptions in Learning Analytics. Journal of Learning Analytics, 2(3), 1-3. 3. http://dx.doi.org/10.18608/jla.2015.23.1

Dawson, S., Mirriahi, N., \& Gasevic, D. (2015). Importance of Theory in Learning Analytics in Formal and Workplace Settings. Journal of Learning Analytics, 2(2), 1-4. http://dx.doi.org/10.18608/jla.2015.22.1

Fundación Ceibal (2016, April). Edumetricas. 1st International Workshop "New Metrics for Evaluation: Towards innovation in learning. Retrieved from http://www.fundacionceibal.edu.uy/en/news/1st-international-workshop-new-metricsevaluation-towards-innovation-learning-edumetricas

Gasevic, D., Dawson, S., Mirriahi, N., \& Long, P. D. (2015). Learning Analytics - A Growing Field and Community Engagement. Journal of Learning Analytics, 2(1), 1-6. Retrieved from https://epress.lib.uts.edu.au/journals/index.php/JLA/article/view/4555/4856

Horn, M. (2014). inBloom's collapse offers lessons for innovation in education. Forbes. Retrieved from http://www.forbes.com/sites/michaelhorn/2014/12/04/inblooms-collapse-offers-lessons-forinnovation-in-education/

Kharif, O. (2014). Privacy fears over student data tracking lead to InBloom's shutdown. Bloomberg. Retrieved from http://www.bloomberg.com/news/articles/2014-05-01/inbloom-shuts-downamid-privacy-fears-over-student-data-tracking

K.N.C. (2014). Withered inBloom. The Economist. Retrieved from http://www.economist.com/blogs/schumpeter/2014/04/big-data-and-education

Mirriahi, N., Dawson, S., Gasevic, D., \& Long, P. D. (2014). Widening the Field and Sparks of the Future. Journal of Learning Analytics, 1(3), 1-3.Retrieved from https://epress.lib.uts.edu.au/journals/index.php/JLA/article/view/4321/4414

Mirriahi, N., Gasevic, D., Dawson, S., \& Long, P. D. (2014). Scientometrics as an Important Tool for the Growth of the Field of Learning Analytics. Journal of Learning Analytics, 1(2), 1-4. Retrieved from https://epress.lib.uts.edu.au/journals/index.php/JLA/article/view/4116

Pardo, A., \& Siemens, G. (2014). Ethical and privacy principles for learning analytics. British Journal of Educational Technology, 45(3), 438-450. http://dx.doi.org/10.1111/bjet.12152

Prinsloo, P., \& Slade, S. (2015). Student privacy self-management: implications for learning analytics. Proceedings of the Fifth International Conference on Learning Analytics and Knowledge, 83-92. http://dx.doi.org/10.1145/2723576.2723585

Roll, I., \& Winne, P. H. (2015). Understanding, evaluating, and supporting self-regulated learning using learning analytics. Journal of Learning Analytics, 2(1), 7-12. Retrieved from https://epress.lib.uts.edu.au/journals/index.php/JLA/article/view/4491/4825

Wise, A. F., \& Shaffer, D. W. (2015). Why Theory Matters More than Ever in the Age of Big Data. Journal of Learning Analytics, 2(2), 5-13. http://dx.doi.org/10.18608/jla.2015.22.2 